\title{
HOW A BEETLE FOLDS ITS WINGS
}

\author{
WM. T. M. Forbes. \\ Cornell University, Ithaca, N. Y.
}

When I was a boy in high school I became interested in insects, and started a collection. Having no adviser to misguide me I carefully pinned all my beetles through the scutellum and spread them like butterflies, which made a curious-looking collection, but developed in me an interest in the wings of beetles that has not yet faded. The title of this paper is one of the first questions that I asked, and one of the many to which I found no answer. The present answer is merely a hint, but I think, correct so far as it goes.

The first suggestion one would make, and I think the one that has been hinted at in the literature, is that the beetle wing is in its resting position straight and stiff, like that of any other insect, and that the beetle folds it and packs it away with the help, perhaps of its hind legs, perhaps of the tip of its abdomen. I think this answer is partly correct, most nearly so in such Clavicorns as the Nitidulidæ and Coccinellidæ, where when the wing is released it snaps open ready for flight. But in the more familiar of the larger beetles, such as the Adephaga and Serricornia, it will be found that the natural condition of the wing is folded, completely or almost completely, and the question arises how the wing is opened, and what holds it stiff for flight. The present paper aims at answering this question.

\section{Serricornia.}

Let us take a beetle of somewhat simple type of folding,the Lampyrid, Telephorus (figs. 1-3). Remove the elytron and pull forward on the costa of the wing. We will find the wing swings out from the body as a folded bundle until it is almost in the flying position, while the anal area unfolds. Finally the anal area is completely unfolded and a strain comes on the disc of the wing. Then suddenly the fanlike fold in the middle of the wing opens, and at the same moment the apex unfolds and flattens out. Now let us see the possible mechanism. 
Represent the principal lines of stiffness in the wing by heavy solid bars, as in figure $3:$ A, B, C, D, E. As A is drawn away from $\mathrm{E}$ the part of the wing lying between them will first unfold like a fan, and soon become tense. I have represented the lines along which the tension is most important by chainlines on the diagram: A1-B1, A2-B2, B2-C, C-D, D-E. The flattening of the basal part of the wing is obvious enough; but the reason why the apex opens is not. so plain. Now let us represent the principal lines of stiffness in each folded area of the apex of the wing in the same way as the basal ones. There are four of these areas, but one is so supported by the surrounding ones that it will be seen to need no support, and a glance at the chitinizations in the wing-substance shows that in fact it has none. The other three may be represented by the bars $\mathrm{K}, \mathrm{N}$ and S. Take K. The inner half of it lies between the bars A and $B$, in such a way that it lies in taut, flat membrane. So any tendency to bend it up or down will draw on the lines of tension A1-B1 and A2-B2, which will elastically support it. A working model can be easily made by looping two rubber bands on two fingers, and then running a match through the two bands (fig. 8). $\mathrm{N}$ is supported in exactly the same way. Then the tips of $\mathrm{K}$ and $\mathrm{N}$ in turn develop a third line of tension (K-N), which, with the help of A2-B2 supports $\mathrm{S}$ in a similar manner. It can be seen that the small folds in the middle of the wing are supported by the tension between $\mathrm{A}$ and $\mathrm{B}$, and so have no structural value. In fact the arrangement of these folds varies a good deal in detail among forms that have essentially this manner of folding, being considerably more complex in the Flateridæ, and especially the Hydrophilidx, and somewhat simplified in such forms as Cebrio and many Buprestidix. These variations are of considerable value in throwing light on relationships, but do not affect the mechanics. In the same way the fourth of the outer areas, below $\mathrm{S}$, (which we may call $\mathrm{T}$ ) is supported by the tension between $\mathrm{S}$ and the apex of $\mathrm{N}$, and needs no structural support of its own. In sum the support of the unfolded wing is due first to the fanlike arrangement of the supports which run from the base, and the tension which muscles in the base put on the first and last of them ( $\mathrm{A}$ and the body behind $\mathrm{E}$ ), and secondly that 
in the outer part each succeeding series of supports overlaps the apex of the preceding, and is held flat by the tension between members of the preceding series. So all folds in the outer part of the wing should necessarily be chevronlike, zigzagging between the apices of an inner, and the bases of an outer series of supports. We find this arrangement very general, not only in the other Serricorns, but even in such aberrant things as the Staphylinidæ; but in the Adephaga a further specialization comes into play.

\section{Adephaga.}

I have chosen Cicindela sexguttata (figs. 3-7) as a fair example of the Adephaga. In general it is typical of the terrestrial Adephagous series, but differs from most Carabidæ in having a strong apical portion of vein $\mathrm{R} 4+5$, supporting the outer part of the wing along the line lettered $\mathrm{M}$ in the diagram. So the details of conditions in the apex will not be duplicated outside of the Cicindelidæ, through the central part of the wing is as in the true Carabids.

Conditions in the base of the wing are exactly as in the Lampyrid, so far as the mechanics is concerned. (The fan-like fold in the vicinity of $\mathrm{M}$ has a different relation to the veins and is probably homologous not to the one so conspicuous in the Lampyrids, but to another below it which appears in many other Polyphaga.) When we come to the principal fold we find that there is no definite chevron-like arrangement that could explain the stiffness of that part, as in the Lampyrid, but that the folds across all the principal veins lie in a straight line. On examining the wing it is found that the stiffness of the outer part of the wing in flying position is wholly due to the curiously constructed costal margin (formed of the fused veins $\mathrm{C}$, Sc and R1) This is rather a flat ribbon than a normal vein, and is also ribbed transversely on its front edge, so that it bends easily from front to back, but is very stiff against any vertical pressure.

Looking at the diagrams (figs. 6 and 7) A, B, D, and E are as in Telephorus. $\mathrm{C}$ is also represented by veins, but is not needed to explain the unfolding of the wing. Next comes F. This bar in the diagram represents an insignificant-looking, but 
in fact very important sclerite which the tracheation shows to be a fragment of vein Rs. It is thrown into a horizontal position and supported by the tension between $\mathrm{A}$ and $\mathrm{B}$, exactly as in the Lampyrid. The fragment of vein $M$ represented by bar $G$ is also apparently of some use, though as it is crossed by one of the folds it must be flexible, and is resistent only to compression. It no doubt helps to fix the bases of $\mathrm{M}$ and $\mathrm{N}$. The outer part of the wing is held flat in a curious way. E as already stated can be bent back, but not up or down, on account of its peculiar structure; and it is attached at its outer end to a large area supported by a complex of strong veins (HILKJ). This area is only kept from bending up or down by the support of E, and is kept forward by the support of the tip of $\mathrm{F}$, which articulates with it and pushes against it, as can be demonstrated by cutting $\mathrm{E}$ and $\mathrm{F}$ in turn. The tip of $\mathrm{J}$ may also get some support from the tip of $\mathrm{G}$, which will help keep the whole area from bending down obliquely by twisting $X$. Altogether the whole area seems very weakly supported, but I can find no other factor. HILKJ, in turn, supports the entire posterior part of the wing by tension in the direction indicated by chain-lines on the diagram. This pull has to act against a strong spring-like action of the root of $\mathrm{O}$, which tends to fold up the wing; and it seems surprising that the bracing of $\mathrm{H}$ by $\mathrm{F}$ is strong enough to do it. The apex of the wing is supported by $\mathrm{S}$ in relation to $\mathrm{I}$ and $\mathrm{M}$, and by $\mathrm{T}$ in relation to $\mathrm{M}$ and $\mathrm{S}$, in much the same way as $\mathrm{S}$ is supported by $\mathrm{K}$ and $\mathrm{N}$ in the Lampyrid.

Other Adephaga show a great deal of variation, especially in the outer part of the wing; but I believe the relation between $\mathrm{X}, \mathrm{F}$ and $\mathrm{H}$, to stiffen the outer part of the wing, is functional in all.

It will be interesting to compare other beetles with these two principal types of folding, and especially to find if any other mechanism is made use of. As I said at the start, I have a strong suspicion that in the various Clavicorn groups there are still other methods of folding, and some seem to make use of the feet. But careful observation of living specimens will be necessary to settle the matter. I hope this paper will attract some good observers to a very interesting problem. 


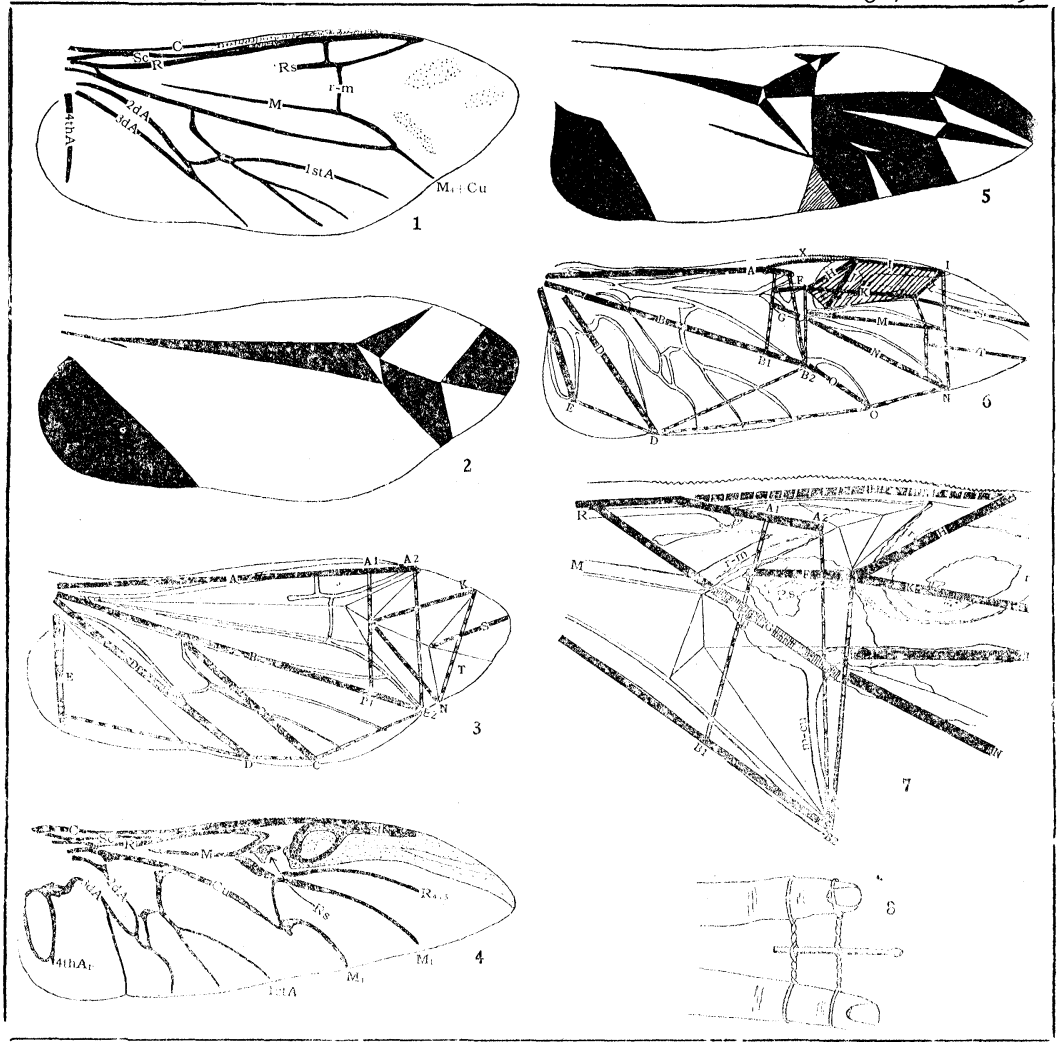

Forbes-Wing Folding in BeEtles

Explanation of Plate 9.

1. Telephorus species (Lampyridæ). Venation.

2. Same. Folding pattern. (Areas reversed in folding black).

3. Same. Mechanics of folding. (Lines of stiffness are represented by heavy solid lines, lines of tension by chain-lines).

4. Cicindela sexguttata (Cicindelidæ). Venation.

5. Same. Folding pattern.

6. Same. Mechanics of folding.

7. Central costal part of fig. 6 , more enlarged.

8. Method of stiffening apical part of wing, illustrated by a model. 

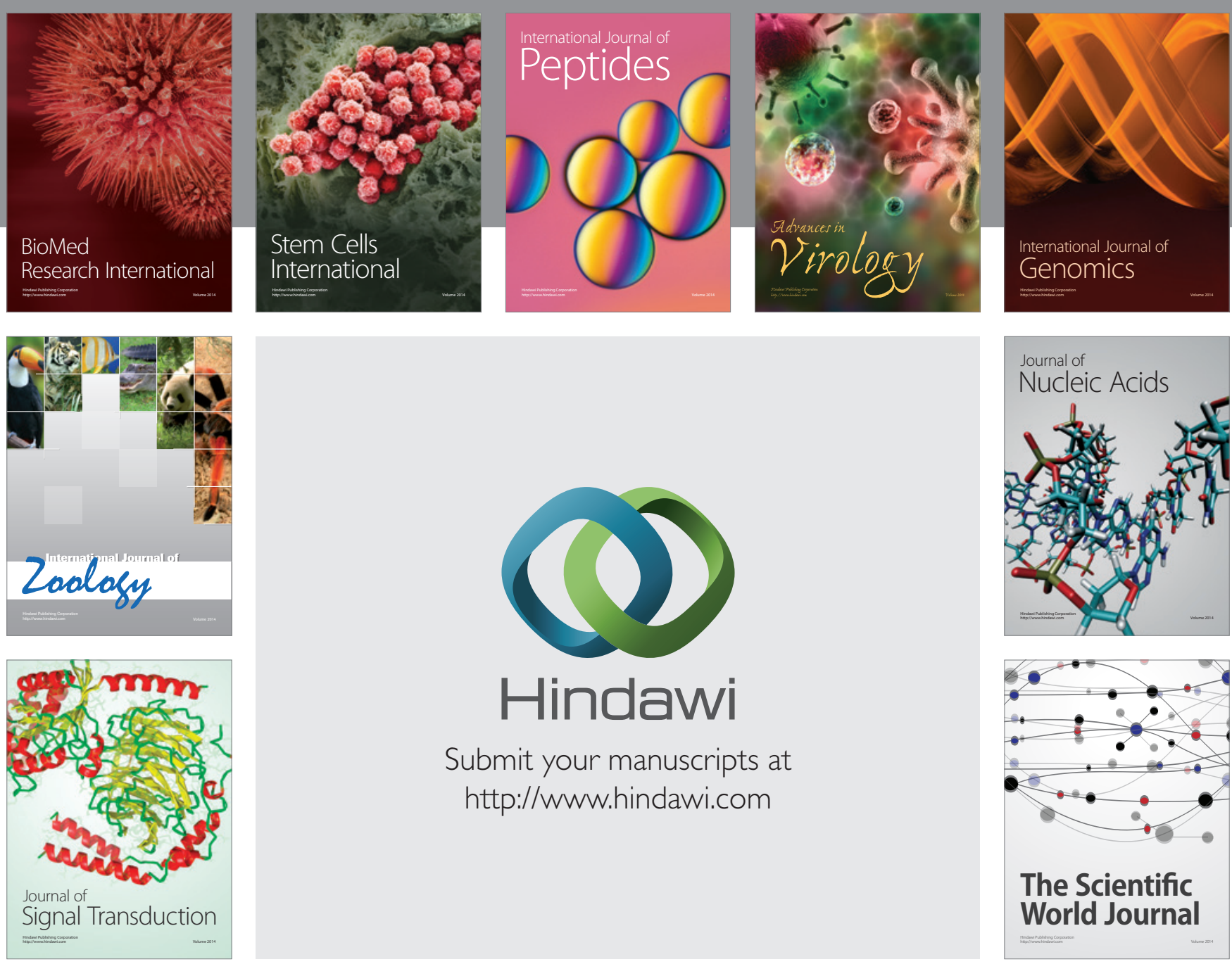

Submit your manuscripts at

http://www.hindawi.com
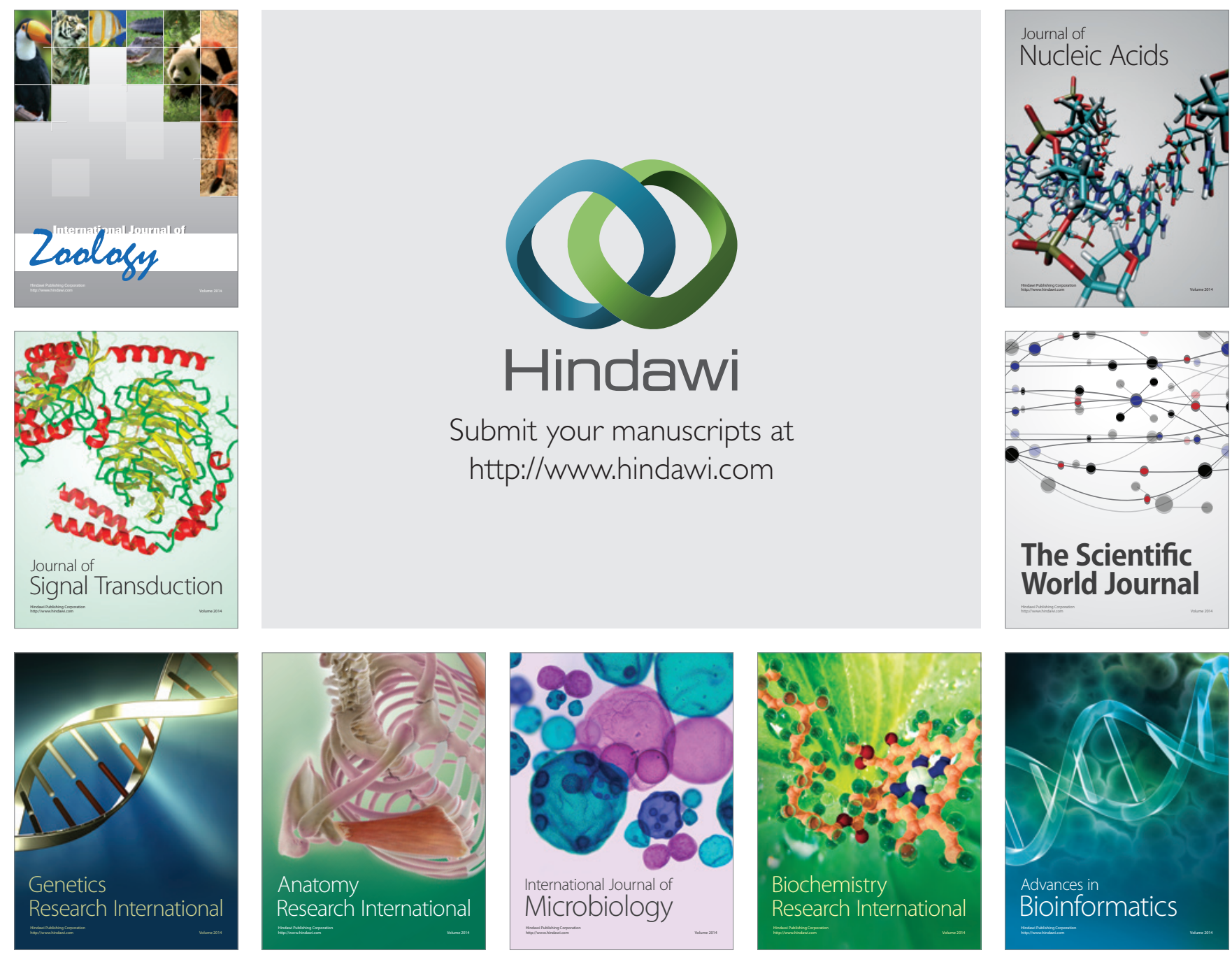

The Scientific World Journal
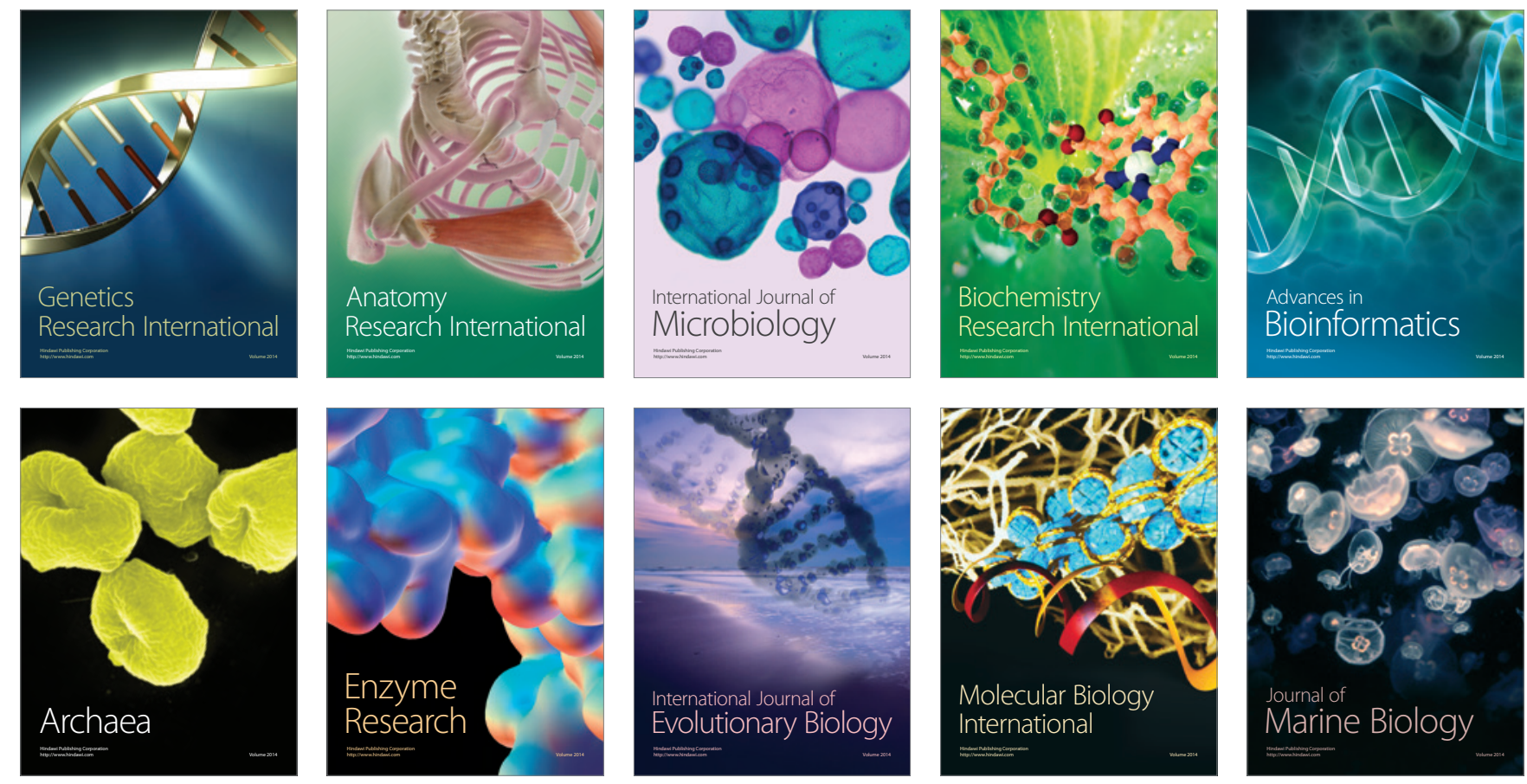